\section{THU0470 WORK AND PROFESSIONAL RECOGNITION IN FIBROMYALGIA PATIENTS - A NATIONAL FRENCH WEB BASED SURVEY ON SICK LEAVE IN 1870 FIBROMYALGIA FEMALE PATIENTS}

F. Laroche ${ }^{1}$, D. Azoulay ${ }^{1}$, J. Guérin ${ }^{1}$, J. Coste ${ }^{2}$, S. Perrot ${ }^{3}$. ${ }^{1}$ Pain Department, Hospital University Saint Antoine, ${ }^{2}$ Biostatistics, Hospital University Hotel Dieu; ${ }^{3}$ Pain Department, Hospital University Cochin, Paris, France

Background: Fibromyalgia (FM) induces work limitations with an increase of number of days of sick leave 3 to 4 fold higher $(1,2)$.

Objectives: Our objectives were to analyze work status, to determine risk factors for sick leave and to compare women working to women in sick leave during the past 12 months in a female population with FM.

Methods: 1870 female workers suffering from FM were selected from a large internet-based national survey of 4516 responders (Fibromyalgie-SOS Association website in France in 2014). Women having a FIRST score $\geq 5 / 6$ were included. Results: 1870 patients participated to the survey: 955 with full time job, 149 with part time job (related to FM status) and 766 on sick leave (7\% 1-3 months, $27.3 \%$ 3-12 months and $62 \%>12$ months). Fibromyalgia Impact questionnaire (FIQ) score was slightly lower in the 1104 patients currently working compared to the 766 on sick leave (56 versus 58.7), but not clinically different. $64,5 \%$ of the population have been on sick leave during the last 12 months (average duration: 37 mean days for full time job and 122 among those with part time job).

Women being in sick leave were older $(p<0,0001)$, single $(p=0,0321)$, had less financial income $(p<0,0001)$, used more antidepressants $(p=0,0085)$ and more anti epileptics $(p=0,0102)$. Recognition of FM by occupational physicians or social security doctors were lower among the workers $(p<0.0001)$.

In the 1104 currently working, more than $33 \%$ have never been visiting their occupational physician and $44,2 \%$ rarely. They reported no support from these doctors $(\mathrm{p}=0,0011)$ particularly those having not being on sick leave. Independent criteria of sick leave were transportation time $(p=0.0131)$, work difficulties $(p=0.0031)$, hinders career progress $(p=0.0196)$, sedentary occupation and repetitive work $(p=0.0195)$.

Conclusions: These data on a large fibromyalgia population shows that clinical status and also professional factors may influence work ability and sick leave.

The work factors include work difficulties, transportation time, sedentary and repetitive occupation. These results should be taken into account by the work professionals in order to facilitate work capacity in FM patients.

References:

[1] Sicras-Mainar A, Rejas J, Navarro R, Blanca M, Morcillo A, Larios R, Velasco $S$ VillarroyaC. Treating patients with fibromyalgia in primary care settings under routine medical practice: a claim database cost and burden of illness study. Arthritis Research \& Therapy 2009, 11:R54.

[2] White K. Comparing self-reported function and work disability in 100 community cases of fibromyalgia syndrome versus controls in London, Ontario: the London Fibromyalgia Epidemiology Study. Arthritis Rheum. 1999;42:76-83.

Acknowledgements: Fibromyalgia SOS french Association.

Disclosure of Interest: None declared

DOI: 10.1136/annrheumdis-2017-eular.3387

\section{THU0471 THE EFFECTS OF TAPPING THERAPY ON PAIN, SYMPTOM SEVERITY, DYSFUNCTIONS IN DAILY LIFE, DEPRESSION, AND QUALITY OF LIFE IN PATIENTS WITH FIBROMYALGIA: A RANDOMIZED CONTROLLED TRIAL}

H.J. Suh ${ }^{1}$, S.T. Choi ${ }^{2}$, J.-S. Song ${ }^{2}$, S.H. Shin ${ }^{3} .{ }^{1}$ Seoul National University Hospital; ${ }^{2}$ Internal Medicine, CHUng-Ang University College of Medicine; ${ }^{3}$ Kyung Hee University Nursing Science, Seoul, Korea, Republic Of

Background: Fibromyalgia is a disorder characterized by chronic widespread musculoskeletal pain, often accompanied by fatigue, cognitive disturbance, psychiatric symptoms, and multiple somatic symptoms. Various pharmacological and non-pharmacological therapies have been tried in the management of fibromyalgia. However, unfortunately, management remains a challenge.

Objectives: Taping therapy has been shown to be effective for pain relief in various musculoskeletal diseases. However, there was no trial for the patients with fibromyalgia. In this study, we evaluated the effects of taping therapy in patients with fibromyalgia.

Methods: This study is a randomized controlled trial with 60 fibromyalgia patients. All patients were satisfied with the 2010 American College of Rheumatology diagnostic criteria for fibromyalgia. Participants were randomized to the Kinesio taping group $(n=30)$ and to the non-elastic paper taping group $(n=30)$ for the control. Taping experiment was performed for three weeks (twice a week) through the one-to-one meeting. Pain, symptom severity, dysfunctions in daily life, depression, and quality of life (QoL) were assessed with the widespread pain index (WPI), severity score (SS), fibromyalgia impact questionnaire (FIQ), Beck depression inventory (BDI), and the EQ-5D INDEX and EQ-5D VAS, respectively. Results: The mean ages of taping group and the control group were $54.3 \pm 12.0$ years and $53.2 \pm 12.7$ years, respectively, and female patients were $25 / 30$ (83.3\%) and $27 / 30(90.0 \%)$ in both groups, respectively, and there were no differences between two groups in the medication use such as anti-depressants and muscle relaxants. Patients showed significant improvements after Kinesio taping therapy in pain $(10.50 \pm 3.98$ vs. $5.70 \pm 2.73, p<0.001)$, symptom severity $(7.93 \pm 2.24$ vs.
$5.27 \pm 1.98, p<0.001)$, dysfunction in daily life $(65.03 \pm 18.75$ vs. $43.25 \pm 18.87$, $p<0.001)$, depression $(18.17 \pm 8.55$ vs. $13.00 \pm 6.75, p<0.001)$ and QoL (EQ5D INDEX, $9.10 \pm 1.54$ vs. $7.67 \pm 1.40, p<0.001$; EQ-5D VAS, $38.33 \pm 24.65$ vs. $56.67 \pm 27.93, p<0.001$ ), respectively. In the control group, however, the significant improvement was detected only in pain $(10.53 \pm 3.87$ vs. $9.27 \pm 3.57, p=0.012)$. The changes before and after treatment in the Kinesio taping group revealed significant differences from those in the control group: pain $(p<0.001)$, symptom severity $(p<0.001)$, dysfunction in daily life $(p<0.001)$, depression $(p=0.001)$ and QoL $(p<0.001$ and $p<0.001)$, respectively. There was no serious adverse event. Conclusions: This study shows that Kinesio taping therapy has effects on pain, symptom severity, dysfunctions in daily life, depression, and quality of life in the patient with fibromyalgia. Taping therapy could be a useful non-pharmacological management modality for the fibromyalgia patient.

Disclosure of Interest: None declared

DOI: 10.1136/annrheumdis-2017-eular.4576

\section{THU0472 FAST3 (FIBROMYALGIA ASSESSMENT SCREENING TEST): A COMPOSITE INDEX BASED ON MDHAQ PROVIDES CLUES TO THE PRESENCE OF SECONDARY FIBROMYALGIA IN PATIENTS WITH A PRIMARY DIAGNOSIS OF RHEUMATOID ARTHRITIS AT HIGHER LEVELS THAN IDENTIFIED IN THE MEDICAL RECORD: A CROSS SECTIONAL STUDY FROM ROUTINE CARE}

I. Castrejon ${ }^{1}$, K. Gibson ${ }^{2}$, J.A. Block ${ }^{1}$, T. Pincus ${ }^{1} .{ }^{1}$ Rheumatology, Rush University Medical Center, Chicago, United States, ${ }^{2}$ Rheumatology, Liverpool Hospital, Sydney, Australia

Background: Secondary fibromyalgia (FM) is reported in $17 \%$ of RA patients ${ }^{1}$ but may be under-recognized in patients with classical RA findings. A FAST3 (fibromyalgia assessment screening test) index based on $3 \mathrm{MDHAQ}$ (Multidimensional Health Assessment Questionnaire) scores gives similar results to ACR fibromyalgia criteria based on a widespread pain questionnaire, ${ }^{2}$ to assist in recognizing patients with secondary $\mathrm{FM}^{3}$.

Objectives: To study patients with a primary diagnosis of RA seen in routine care for the proportion identified as having secondary FM according to a physician diagnosis in the medical record versus a FAST3 Index of MDHAQ scores.

Methods: All patients complete an MDHAQ/RAPID3 at all visits in the waiting area in routine care. The MDHAQ includes $0-10$ scores for physical function, pain, and patient global estimate, compiled into RAPID3, as well as a $0-48$ RADAl self-report score of painful joints, and 0-60 symptom checklist. FAST3 has been developed previously as the $0-3$ sum of 1 point each for 3 MDHAQ scores: pain VAS $\geq 6$, RADAI $\geq 16$, and symptom checklist $\geq 16 .{ }^{3}$ FAST scores of $>2 / 3$ had $>80 \%$ agreement with ACR FM criteria based on a widespread pain questionnaire ${ }^{2}$ to identify secondary $\mathrm{FM}^{3} \mathrm{~A}$ random visit for each patient with a primary diagnosis of RA with complete data was studied. The number with a diagnosis of secondary FM in the medical record was compared to the number with FAST3 scores of $0,1,2,3$, and with each of the 3 FAST3 components. Receiver-operating characteristic $(\mathrm{ROC})$ curves were generated to estimate sensitivity and specificity for each cut-point of the FAST3 score, using a diagnosis of secondary FM by the physician as the external criterion.

Results: 287 patients with RA were studied, of whom $10(3.3 \%)$ had a diagnosis of secondary FM by the physician in the medical record and 61 (22\%) had FAST3 scores of 2 or 3 (Table), including 6 of 10 identified as having FM in the medical record. Overall, FAST3 was 0 in 161 RA patients (56\%), 1 in $59(20.6 \%), 2$ in $46(16 \%)$, and 3 in $21(7.3 \%)$ (Table). Overall, 55 additional RA patients were identified by FAST3 versus the medical record as having possible secondary FM. The ROC area was $0.73(95 \% \mathrm{Cl}, 0.57-0.89)$ (data not shown).

Table 1. FAST3 (fibromyalgia assessment screening tool) Index and 3 individual components according to diagnosis of fibromyalgia by rheumatologist in medical record

\begin{tabular}{lccc}
\hline & Clinical FM-No & Clinical FM-Yes & Total \\
\hline Total & 277 & 10 & \\
FAST (fibromyalgia assessment screening tool) Index & & \\
0 & $159(57 \%)$ & $2(20 \%)$ & 161 \\
1 & $57(21 \%)$ & $2(20 \%)$ & 59 \\
2 & $42(15 \%)$ & $4(40 \%)$ & 46 \\
3 & $19(7 \%)$ & $2(20 \%)$ & 21 \\
Individual component measures & & & \\
Pain $>6$ & $92(33 \%)$ & $7(70 \%)$ & 99 \\
Pain $<6$ & $185(67 \%)$ & $3(30 \%)$ & 188 \\
RADAI $>16$ & $68(25 \%)$ & $6(60 \%)$ & 74 \\
RADAI $<16$ & $209(75 \%)$ & $4(40 \%)$ & 213 \\
Symptom checklist $>16$ & $38(14 \%)$ & $3(30 \%)$ & 41 \\
Symptom checklist $<16$ & $239(86 \%)$ & $7(70 \%)$ & 246 \\
\hline
\end{tabular}

Conclusions: The same MDHAQ used to score RAPID3 may also provide a FAST3 score as a screening tool for secondary FM in RA (and other) patients (including primary FM). Secondary FM may be under-diagnosed by clinicians in routine care. Further validation of FAST3 in other settings is needed.

References:

[1] Wolfe F, et al. J Rheum 2011:31:695-700

[2] Wolfe et al, J Rheumatol 2011;38:1113-22.

[3] Gibson K, et al. Arthritis Rheumatol. 2016; 68 (suppl. 10). 
Disclosure of Interest: I. Castrejon: None declared, K. Gibson: None declared, J. Block: None declared, T. Pincus Shareholder of: Health Report Services, Inc DOI: 10.1136/annrheumdis-2017-eular.5209

\section{THU0473 POLYSYMPTOMATIC DISTRESS SCALE, WIDE SPREAD PAIN INDEX, AND SYMPTOM SEVERITY SCALES, AND THEIR CORRELATES IN 169 PATIENTS WITH FIBROMYALGIA SYNDROME}

K. Yaseen ${ }^{1}$, S. Kaouk ${ }^{2}$, D. Bork ${ }^{3}$, W.S. Wilke ${ }^{3}$, C. Gota ${ }^{3} .{ }^{1}$ Internal Medicine, Cleveland Clinic; ${ }^{2}$ Rheumatology, John Carroll University; ${ }^{3}$ Rheumatology, Cleveland Clinic, Cleveland, United States

Background: The polysymptomatic distress scale (PSD) is considered a measure of FM severity and ranges from 0 to 31 . It is calculated by adding the two components of the American College of Rheumatology (ACR) 2010 fibromyalgia (FM) criteria, widespread pain index (WPI) and symptoms severity scale (SS).

Objectives: Determine the relationship between depression, anxiety, function disability and pain related disability, with fibromyalgia severity as measured by PSD and its subsets, WPI and SS.

Methods: All consecutive FM patients who met the ACR 2010 criteria completed the following questionnaires: $\mathrm{PSD}$, patient health related questionnaire (PHQ-9), a measure of depressive symptoms, general anxiety disorder questionnaire (GAD-7), health assessment questionnaire disability index (HAQ-DI), and pain disability index (PDI).

Results: Of 169 patients, 85.7\% were women, mean age 42.3 (13.3), BMI 29.3 (7.1), PHQ-9 13.7 (5.2), GAD-7 10.2 (9.1), HAQ-DI 1.6 (2.9), PDI 6 (2.1), WPI 14.3 (2.7), SS 10 (1.6). In univariate analysis PSD correlated significantly $(p<0.01)$ with PHQ-9 (0.576), PDI (0.422), and GAD-7 (0.356). Widespread pain index correlated significantly with PHQ-9 (0.313), GAD-7 (0.239), HAQ-DI (0.259), and PDI (0.296). Symptom severity scale correlated significantly with PHQ-9 (0.496), GAD-7 (0.337), HAQ-DI (0.275), PDI (0.340). A linear regression analysis model, which included PHQ-9, GAD-7, PDI and HAQ-DI predicted 0.269 of $P S D$ variance, $p=0.001$, and only $P D I$ remained significantly correlated with PSD. A similar model predicted 0.348 of SS variance, $(P<0.0001)$, and only PHQ-9 remained significantly correlated with SS. This model did not significantly predict WPI variability.

Conclusions: Depression, anxiety, pain disability and functional disability predict a small variance of fibromyalgia severity measured by PSD. In regression analysis, pain disability measured by PDI is the only variable that remains independently correlated with PSD. None of these variables predicted WPI, while depression measured by PHQ-9 remains independently correlated with SS, indicating that PSD subsets measure different dimensions of FM.

Disclosure of Interest: None declared

DOI: 10.1136/annrheumdis-2017-eular.4343

\section{THU0474 A CROSS-SECTIONAL STUDY INTO THE EFFECTIVENESS OF THE FIBROMYALGIA RAPID SCREENING TOOL FOR DETECTING FM IN PATIENTS WITH CHRONIC ARTHRITIS UNDERGOING FULL AND TAPERED BIOLOGICAL DISEASE-MODIFYING ANTIRHEUMATIC DRUG THERAPY}

L. Valor, D. Hernández Flórez, T. del Río, I. Janta, J. Martínez Barrio, J.G. Ovalles B., B. Serrano, R. González Benítez, C. Sáenz Tenorio, J.C. Nieto, C. González, I. Monteagudo, F.J. López-Longo. Rheumatology, Hospital General Universitario Gregorio Marañón, Madrid, Spain

Background: The determination of fibromylagia (FM) in patients presenting diffuse, chronic arthritis is fraught. The Fibromyalgia Rapid Screening Tool (FiRST) is a validated questionnaire with high sensitivity and moderate specificity shown to be able to identify up to $89 \%$ of FM cases, even when accompanied by anxiety, depression or functional disability. Decisions to embark upon a course of full or tapered biological disease-modifying antirheumatic drugs (bDMARD) are influenced in part by patient self-assessment scores as well as concomitant pathologies.

Objectives: To evaluate the prevalence of FM using the FiRST questionnaire in bDMARD-treated chronic arthritis patients.

Methods: This cross-sectional study included 325 patients [178 $(54,8 \%)$ females and $147(45,2 \%)$ males] diagnosed with chronic arthritis and treated with bDMARD. Patients were consecutively recruited from the Biological Therapy Unit from January to March 2015 all having undergone full or tapered bDMARD for at least 1 year. Dosage tapering had been applied to patients considered to be in remission. All patients self-completed the FiRST questionnaire with a score $>5 / 6$ considered positive. Clinical assessment was carried out by one specialist only. Demographic, clinical and laboratory variables were recorded with pathologyspecific indices used to assess disease status, i.e.DAS28-ESR, DAS28-CRP, SDAI, CDAI, BASDAI, BASFI, ASDAS-CRP. Patient pathologies were classified as peripheral arthritis (PerAR: RA, PsA, PerSpA) or axial spondyloarthropathy type (AxSpA)

Results: A total of $68 / 325(21 \%)$ patients scored $>5 / 6$ in the FiRST. Disease duration and previous bDMARD usage were not significant regarding scores $<5 / 6$. In the PerAR vs. AxSpA group, we observed that $19 \%(n=43)$ and $35 \%(n=25)$ scored FiRST $>5 / 6$, respectively $(p=N S)$. Fifteen per cent of patients with tapered
bDMARD registered scores $>5 / 6$ against $85 \%$ of patients in full bDMARD dosage $(p=0.001)$. There were a higher number of remission patients in the PerAR group as defined under DAS28-ESR, SDAI and CDAI [(96\%, 94\% and 94\%) $(p=0.01$, $\mathrm{p}=0.04, \mathrm{p}=0.032$ ), respectively]. Association was found in the PerAR subgroups between tapered bDMARD and remission in RA patients only, as defined under DAS28-VSG, SDAI and CDAI ( $p=0.026, p=0.04, p=0.043$, respectively). In the AxSpA tapered bDMARD subset, $86 \%$ of patients were considered to be in clinical remission as set out under BASDAI $(p=0.019)$.

Conclusions: No difference was observed between the PerAR and AxSpA groups for FiRST>5/6. Fewer patients undergoing tapered bDMARD dosage recorded FiRST scores $>5 / 6$. Therefore, early identification of chronic arthritic patients presenting FiRST $>5 / 6$ may prove to be an important step in furthering understanding of clinical activity in diffuse arthritis as well as offering improved diagnostic and therapeutic outcomes to bDMARD-treated patients with possible concomitant FM.

Disclosure of Interest: None declared

DOI: 10.1136/annrheumdis-2017-eular.4768

\section{THU0475 EVALUATION OF PELVIC FLOOR STRENGTH AND URINARY INCONTINENCE IN WOMEN WITH FIBROMYALGIA}

M.A.G. Pontes Filho ${ }^{1}$, H.C.S.C. Fusco ${ }^{2}$, E.A.G. Ferreira ${ }^{2}$, A.P. Marques ${ }^{2}$. $^{2}$

${ }^{1}$ Reumatologia, Hospital das Clínicas da Faculdade de Medicina da Universidade de São Paulo; '2Fisioterapia, Fonaudiologia e Terapia Ocupacional, Universidade de São Paulo, Sao Paulo, Brazil

Background: Fibromyalgia (FM) is characterized by the American College of Rheumatology as chronic widespread pain referred for at least 3 months. In 2010 , a new diagnostic criteria was proposed and includes symptoms such as fatigue, sleep disorder and memory. Currently, pelvic floor dysfunctions and urinary incontinence (UI) are considered public health problems with high prevalence and great impact on quality of life (QoL) and on women's self-esteem. Physiotherapists have been working to create a new treatment proposal that can cover all aspects of FM, however there are few studies that include pelvic floor evaluation and urinary continence of this population.

Objectives: To assess the strength of the pelvic floor and urinary loss in women with FM.

Methods: We evaluated 126 sexually active women, aged between 19 and 65 years, with and without medical diagnosis of FM, matched for age and menopausal status, in a single center. The exclusion criteria were sexually transmitted or neurological diseases, pregnancy and use of medications with urinary side effects (urinary loss or retention). We collected in a single interview personal and gynecological data, applied the King Health Questionnaire (KHQ) for incontinent women and accomplished the evaluation of pelvic floor muscle strength according to the Oxford Classification Modified and perineometry. The participants signed the Informed Consent Form. We used for statistical analysis t test for independent variables and Mann-Whitney Test for the others.

Results: The FM patients presented the weaker pelvic floor $(p<0.001)$ and had lower values in perineometry $(p=0.04)$ than control women. Regarding urinary loss, $64.5 \%$ reported $\mathrm{UI}$ against $26.6 \%$ of women without FM. In the $\mathrm{KHQ}$ evaluation, in General Health and Emotions domains, women with FM presented worse performance $(p<0.001$ and $p=0.046$, respectively).

Conclusions: Urinary incontinence is a frequent finding in FM, and it could be related to the degree of strength of the pelvic floor muscles. This condition affects negatively QoL, especially with regard to emotions and general health.

References:

[1] Wolfe, et al. The American College of Rheumatology Preliminary Diagnistic Criteria for Fibromyalgia and Measurement of Symptom Severity. Arthritis Care \& Research, v.2, n.5, pg. 600-610, 2010.

[2] Jones, K. D. et al. Pelvic Floor and Urinary Distress in Women with Fibromyalgia. Pain Management Nursing, v. 16, n. 6, p. 834-840, Dec 2015. Acknowledgements: This study received funds from CAPES (Coordination for the Improvement of Higher Education Personnel - Government Research Agency) with scholarship to one of the co-authors.

Disclosure of Interest: None declared

DOI: 10.1136/annrheumdis-2017-eular.6261

\section{THU0476 EVALUATION OF SEXUAL FUNCTION IN WOMEN WITH FIBROMYALGIA}

M.A.G. Pontes Filho ${ }^{1}$, H.C.S.D.C. Fusco ${ }^{2}$, R.T. Cônsolo ${ }^{2}$, E.A.G. Ferreira ${ }^{2}$ ${ }^{1}$ Reumatologia, Hospital das Clínicas da Faculdade de Medicina da Universidade de São Paulo; ${ }^{2}$ Fisioterapia, Fonaudiologia e Terapia Ocupacional, Universidade de São Paulo, Sao Paulo, Brazil

Background: Fibromyalgia (FM) is defined by the American College of Rheumatology as a syndrome of unknown etiology, characterized by chronic and widespread musculoskeletal pain. In 2010, a new diagnostic criteria was proposed and involves not only pain but symptoms such as depression, muscle fatigue, non-restorative sleep and urinary disorders. This may lead to a lack of interest or difficulty in the sexual act, which tends to be aggravated by depression, which is manifested by low self-esteem, decreased desire and orgasm, and pain during sexual intercourse. 